Applied Soil Ecology 127 (2018) 30-40

\title{
Simultaneous application of two herbicides and green compost in a field experiment: Implications on soil microbial community
}

C. García-Delgado, V. Barba, J.M. Marín-Benito, J.M. Igual, M.J. Sánchez-Martín, M.S. Rodríguez-Cruz*

Instituto de Recursos Naturales y Agrobiología de Salamanca (IRNASA-CSIC), Cordel de Merinas 40-52, 37008 Salamanca, Spain

\section{*Corresponding author.}

E-mail address: msonia.rodriguez@irnasa.csic.es

Tel.: +34 923219606. Fax: +34923219609

\section{Author's e-mails:}

C. García-Delgado: carlos.garcia@irnasa.csic.es

V. Barba: victor.barba@irnasa.csic.es

J.M. Marín-Benito: jesusm.marin@irnasa.csic.es

J.M. Igual: mariano.igual@irnasa.csic.es

M.J. Sánchez-Martín: mjesus.sanchez@irnasa.csic.es

M.S. Rodríguez-Cruz: msonia.rodriguez@ irnasa.csic.es 


\section{Highlights}

- Effects of herbicides and green compost on soil microbiology were evaluated at field scale

- Green compost decreased the dissipation rate of triasulfuron, but no that of prosulfocarb

- Combined application of triasulfuron and prosulfocarb modified soil microbial community

- Green compost buffered the effects of herbicides on soil microbial activity and structure 


\section{Abstract}

2 The simultaneous use of herbicides and organic amendments is a common agricultural 3 practice that may modify the behavior of the herbicides themselves and affect the 4 microbial community in soils. There is little information about the changes in the soil

5 microbial community by this agricultural practice under real field conditions. The aim

6 of this work was to assess the effects on the soil microbial community (abundance, 7 activity, and structure) of the following two herbicides triasulfuron (TSF) and 8 prosulfocarb (PSC) applied as individual or combined formulations in an unamended 9 soil (Soil) and in a soil amended with green compost (Soil+GC) at field scale. Herbicide dissipation, soil biomass, respiration, dehydrogenase activity (DHA), and the profile of phospholipid fatty acids (PLFA) were monitored for 100 days. Triasulfuron recorded a slower dissipation rate than PSC. The dissipation rate of TSF decreased in the GCamended soils compared to the unamended ones. Furthermore, the Soil+GC recorded a higher soil biomass and respiration than the unamended ones. In the GC-amended soil, biomass values decreased with individual or combined TSF application compared to the Soil+GC control, while biomass values in the unamended soil increased with the application of combined herbicides after 100 days. In general, soil respiration values decreased with the application of herbicides in both the unamended and GC-amended soils. This negative effect was higher for the combined TSF+PSC application. DHA values decreased over time in the unamended soils treated with herbicides, but this decrease was not observed in the GC-amended soil. The microbial structure clearly changed throughout the experiment under the different conditions assayed. After 100 days of simultaneous TSF+PSC application, there was a significant increase in Grampositive bacteria and a significant decrease in Gram-negative bacteria and Actinobacteria in the unamended soil. The GC-amended soil minimized the effects of 
$\mathrm{TSF}+\mathrm{PSC}$, and only the relative abundance of Actinobacteria increased at 100 days. The microbial community in the unamended and GC-amended soils behaved differently with herbicide application; however, the combined application of TSF and PSC altered soil microbial activity and structure compared to their individual application or nonapplication. The application of GC to soil buffered the impact of TSF and PSC on microbial biomass and activity, and reduced the shift in the soil microbial structure.

Keywords: triasulfuron, prosulfocarb, organic amendment, soil microbiology, field

\section{Introduction}

The application of pesticides in modern agriculture is a widespread practice around the world designed to increase crop yields (Imfeld and Vuilleumier, 2012). However, the extensive use of these chemicals also releases pollutants into the environment (HerreroHernández et al., 2016; Pose-Juan et al., 2015b; Sánchez-González et al., 2013). Given the toxic nature of pesticides, considerable effort has been made to monitor, understand and minimize their environmental impact (Herrero-Hernández et al., 2016, 2015; Odukkathil and Vasudevan, 2013).

In this respect, the application of organic amendments to the soil could act as a barrier to avoid pesticide leaching, minimizing the spread of pollutants (Álvarez-Martín et al., 2016b; Marín-Benito et al., 2017, 2013). On the other hand, the use of organic amendments is a common practice in agriculture and in soil remediation processes for increasing the soil content of nutrients and organic carbon (OC) (Clemente et al., 2015; Medina et al., 2012). This agricultural practice improves soil properties and crop yield, and enhances soil microbial activity (López-Rayo et al., 2016; Medina et al., 2015; Zornoza et al., 2016). Organic amendments can inoculate new microorganisms in the 
soil or promote the growth of specific microorganisms that modify the soil's microbial activity and structure (Álvarez-Martín et al., 2016a; García-Delgado et al., 2015; Sun et al., 2017).

However, organic amendments may also modify the persistence and dissipation of pesticides in soils by increasing soil OC (Marín-Benito et al., 2014, 2013, 2012). In some cases, organic amendments have led to a decrease in the half-life of a pesticide, while in others there was an increase or even no effect at all (Álvarez-Martín et al., 2016a; Hussain et al., 2015; Marín-Benito et al., 2014). As the application of organic amendments affects the behavior of pesticides in the soil, they will be able to regulate the bioavailability and concentration of pesticides in the soil solution, conditioning their possible impact on soil microbial communities. Therefore, the soil microbial community's function and activity could be affected by the simultaneous application of pesticides and organic amendments (Hussain et al., 2009; Pose-Juan et al., 2015a).

Information about the effects pesticides have on soil microorganisms and assessing the toxicity of these compounds for soil microbial communities is increasing nowadays due to is a pre-requisite for improving pesticide regulation in the short term (Karpouzas et al., 2014). According to the reviews by Hussain et al. (2009) and Imfeld and Vuilleumier (2012), the presence of pesticides and their degradation products in the soil may inhibit, promote, or have no effects on microbial diversity and its functions. Therefore, considering the inconsistent results and the significance of microbial biomass, diversity and activity in many soil cycles and soil health, there is considerable scientific interest in determining the impact pesticides has on the soil microbial community (Martin-Laurent et al., 2010). 
Moreover, there is little information about the soil microbial community's response and function when pesticides and organic residues are simultaneously applied (Pose-Juan et al., 2017, 2015a). Many of the published studies on soil microbial community's response to pesticides have been conducted at laboratory or greenhouse scale (Cycoń et al., 2012, 2013; Karpouzas et al., 2014; Pose-Juan et al., 2017, 2015a), while field-scale assays that replicate real conditions are scarce (Petric et al., 2016; Spyrou et al., 2009).

The largest share of pesticides involves herbicides, which play key roles in promoting crop yields. These compounds have also posed serious issues of environmental pollution (Huang et al., 2016), and soil bacteria are sensitive to some of them, such as sulfonylureas, affecting the universal biological processes in living systems (Patyka et al., 2016).

Two groups of herbicides widely used today are sulfonylureas and thiocarbamates. They have good selectivity, and are characterized by broad-spectrum weed control for many cereal crops, such as rice, wheat or maize, soybean and sugar beet or vegetables (e.g., carrots, peas, and potatoes) (Sofo et al., 2012). Triasulfuron is a sulfonylurea that inhibits the behavior of acetolactate synthase, and it is responsible for the biosynthesis in plants and bacteria of three branched-chain amino acids (leucine, isoleucine, and valine). Since the enzyme is absent in humans and animals, it is a safe choice to apply sulfonylureas in the field (Wang et al., 2010). Triasulfuron is a weak acid which presents a high solubility in water and low hydrophobicity. In field dissipation studies, TSF exhibited an elevated mobility and moderate persistence in soils (PPDB, 2017). The time required for the concentration to decline to half of the initial value $\left(\mathrm{DT}_{50}\right)$ ranged between 15.9 and 65.4 days (EFSA, 2015). The adsorption of TSF by soils influences its biodegradation and bioavailability (Said-Pullicino et al., 2004). Its 
transformation to metabolites is due to microbial degradation and chemical hydrolysis (Pose-Juan et al., 2017; Singh and Kulshrestha, 2006). Soil bacterial communities or activities could be affected by this herbicide (Pose-Juan et al., 2017; Wang et al., 2010). Nevertheless, little is currently known about the impact TSF and other sulfonylurea herbicides have on soil microbes (Karpouzas et al., 2014).

Thiocarbamate herbicides inhibit the elongase enzyme, hence the main effect of these herbicides is the inhibition of the synthesis of very-long-chain fatty acids, while also affecting meristematic tissues. Among these herbicides, and as a secondary effect, PSC has previously been reported to inhibit shikimate synthesis, leading to a decrease in flavonoid content and a variation in amino acid composition and content. The changes can be interpreted as secondary effects, probably related to the stress caused by the primary effects of PSC (Hjorth et al., 2006). Prosulfocarb has low solubility in water and high hydrophobic character. This herbicide presents high adsorption, is slightly mobile and non-persistent in soils (PPDB, 2017). Under field conditions, prosulfocarb $\mathrm{DT}_{50}$ values ranged between 6.5 and 13.0 days (EFSA, 2007). The dissipation of PSC is due mainly to microbial degradation (Gennari et al., 2002). The high adsorption of PSC by soil organic matter fractions could lead to a decrease in leaching (Nègre et al., 2006).

The physicochemical behavior of TSF and PSC herbicides, including their dissipation, mobility and persistence in a field experiment in an unamended soil and one amended with green compost (GC), has been evaluated in a previous study (Marín-Benito et al., 2018). Herbicide concentrations were determined at various times in the surface soil and at different depths up to $50 \mathrm{~cm}$ to evaluate the effect of the increased $\mathrm{OC}$ in the amended soil and the influence on the dissipation and mobility of individual Logran ${ }^{\circledR}$ and Auros ${ }^{\circledR}$, or the combined commercial formulation Auros Plus ${ }^{\circledR}$ of both compounds. 
The present work supports a simultaneous study designed to evaluate the effect of herbicides applied on microbial communities and their evolution over the dissipation process. To our knowledge, there are no studies on the impact of PSC on soil microbial communities, and little is known about the impact of TSF on soil microbes under real field conditions (Karpouzas et al., 2014).

Accordingly, the aim of this work was to determine the possible modifications of soil microbial communities due to the application of the herbicides TSF and PSC on an unamended and a GC-amended soil. A field experiment was set up, and the effects of the individual or combined commercial formulations of the herbicides were studied on the following: (i) the soil microbial biomass, respiration, and dehydrogenase activity, as parameters indicating the abundance, overall activity and function of microbial communities, and (ii) the profile of phospholipid fatty acids (PLFAs) extracted from the soil, as indicator of the soil microbial structure. Changes were evaluated at various times during the dissipation of herbicides in the soil surface.

\section{Materials and methods}

\subsection{Herbicides}

This study used the commercial formulations of triasulfuron (TSF) (Logran ${ }^{\circledR} 20 \% \mathrm{p} / \mathrm{p}$ ), prosulfocarb (PSC) $\left(\right.$ Auros $\left.^{\circledR} 80 \% \mathrm{p} / \mathrm{v}\right)$, and triasulfuron + prosulfocarb (TSF+PSC) (Auros Plus $^{\circledR}$ ) (Syngenta Agro S.A., Madrid, Spain). Analytical standards of both compounds were purchased from PESTANAL ${ }^{\circledR}$ (purity > 98.9\%) (Sigma Aldrich Química S.A., Madrid, Spain). The chemical name, structure and characteristics of these compounds are included in Table S1 (in Supplementary material) (PPDB, 2017).

\subsection{Green compost}


143 A composted organic residue of vegetal origin from the pruning of plants and trees in parks and gardens in the city of Salamanca (Spain) has been used. It was supplied by the city council. The physicochemical characteristics of this green compost (GC) on a dry weight basis are as follows: $\mathrm{pH} 7.33$, determined in a GC/water suspension (1:2); OC content $9.80 \%$, determined by the modified Walkley-Black method; dissolved organic carbon (DOC) $0.353 \%$, determined in a suspension of GC in deionized water (1:2) after shaking (24 h), centrifugation (20 min at $10000 \mathrm{rpm}$ ) and filtering, using a Shimadzu 5050 (Shimadzu, Columbia, MD, USA) organic carbon analyzer; total N, $1.04 \%$ determined by the Kjeldahl method. The $\mathrm{C} / \mathrm{N}$ rate was 9.42 , and the ash percentage determined by weight difference after ignition at $540^{\circ} \mathrm{C}$ for $24 \mathrm{~h}$ was $74.5 \%$.

A field experiment was conducted with an agricultural sandy clay loam soil (Typic Haploxerept) (Soil Survey Staff, 2010) on the Muñovela experimental farm belonging to the Institute of Natural Resources and Agrobiology of Salamanca (IRNASA-CSIC), Spain ( $40^{\circ} 55^{\prime} 56^{\prime \prime} \mathrm{N}$ latitude and $5^{\circ} 52^{\prime} 53^{\prime \prime} \mathrm{W}$ longitude). A detailed description of the experimental layout of randomized complete blocks of unamended soil (Soil) (12 plots) and soil amended with GC (Soil+GC) at the rate of $120 \mathrm{t} \mathrm{ha}^{-1}$ on a dry weight basis ( 11.6 $\mathrm{t} \mathrm{C} \mathrm{ha}^{-1}$ ) (12 plots) and of the weather conditions is included in Supplementary material and in Marín-Benito et al. (2018).

Water herbicide suspensions were applied manually using a backpack sprayer (volume of $10 \mathrm{~L}$ ) seven days after the soil was amended. The doses applied to the plots were in the ranges of the recommended application doses for both herbicides $\left(4.5 \mathrm{~kg}\right.$ i.a. ha ${ }^{-1}$ as Auros $^{\circledR} 80 \%$ (PSC), and 100 g i.a. ha ${ }^{-1}$ as Logran ${ }^{\circledR} 20 \%$ (TSF)). Similar doses of both compounds were applied jointly as Auros Plus ${ }^{\circledR}$ (TSF+PSC). The combination of soil 
management, unamended (Soil) and amended with GC (Soil+GC), and herbicides application (TSF, PSC or TSF+PSC) denoted the treatments applied. A check was made prior to the application of the herbicides to ensure that no amounts of these compounds were detectable in the soil samples. This was as expected, because the plots had no record of TSF and PSC application in the previous five years.

Surface soil samples from 0 to $10 \mathrm{~cm}$ were collected on the first day after herbicide application (0 days), and at 30 and 100 days after treatment to determine soil biomass, dehydrogenase activity (DHA), respiration, and phospholipid fatty acids (PLFAs) in all the treatments. Soil samples were also collected at the same times to determine herbicide dissipation. Five sub-samples were taken in each plot, mixing them before they were transferred to polypropylene bottles. All the samples were transported to the laboratory in portable refrigerators. Soil samples were divided into sub-samples to determine soil biomass, respiration, DHA and herbicide dissipation, which were analyzed immediately. To determine PLFAs, the samples were frozen at $-80^{\circ} \mathrm{C}$ and lyophilized prior to extraction and analysis. Soil characteristics were determined according to Marín-Benito et al. (2018), and are included in Supplementary material (Table S2).

Duplicate subsamples of moist soil (6 g) were extracted from each plot with methanol $(12 \mathrm{~mL})$ to determine herbicide residues. The samples were sonicated for $1 \mathrm{~h}$, shaken at $20^{\circ} \mathrm{C}$ for $24 \mathrm{~h}$, and then centrifuged at $5045 \mathrm{~g}$ for $15 \mathrm{~min}$. The extracts were filtered to remove particles $>0.45 \mu \mathrm{m}$ in a GHP Acrodisc filter (Waters Corporation) and evaporated until dryness at $25^{\circ} \mathrm{C}$ under a nitrogen stream using an EVA-EC2-L evaporator (VLM GmbH, Bielefeld, Germany). The residue was dissolved in $0.5 \mathrm{~mL}$ of 
methanol + formic acid (1\%), and transferred to a HPLC glass vial for analysis. The analysis of TSF and PSC was performed by HPLC attached to a ZQ mass spectrometer detector (MS) (Waters Assoc., Milford, MA, USA). A detailed description of the analytical method is included in Supplementary material.

\subsection{Soil biochemical properties and PLFA analysis}

Microbial biomass-N was extracted using the chloroform fumigation-extraction technique (Vance et al., 1987). Cytoplasm content was extracted with $\mathrm{K}_{2} \mathrm{SO}_{4}$, and the ammonium present was determined by colorimetry with a segmented flow autoanalyzer. A conversion factor into biomass-C of 21 was used (García-Izquierdo, 2003).

Soil respiration was determined by measuring the depletion of pressure produced by $\mathrm{O}_{2}$ consumption by the microorganisms in $50 \mathrm{~g}$ of fresh soil over four days using OxiTop Control BM6 containers with an OxiTop Control OC 110 measurement system (WTW, Weilheim, Germany). The $\mathrm{CO}_{2}$ produced by the metabolism of soil microorganisms was trapped in $10 \mathrm{~mL}$ of $\mathrm{NaOH} 1 \mathrm{M}$.

Soil DHA is a measure of overall microbial activity. This parameter was determined by the method of Tabatabai modified by Singh et al. (2002). Briefly, six grams of fresh soil were mixed with $60 \mathrm{mg}$ of calcium carbonate and $1 \mathrm{ml} \mathrm{3 \%}$ 2,3,5-triphenyltetrazolium chloride and $2.5 \mathrm{~mL}$ of ultrapure water. The reaction mixture was incubated at $37^{\circ} \mathrm{C}$ for $24 \mathrm{~h}$ in the dark. At the end of incubation, the 1,3,5-triphenylformazan (TPF) was extracted with $7 \mathrm{~mL}$ of methanol, centrifuged (3000 rpm,10 min) and extracted two times again. The three fractions were mixed and diluted to $25 \mathrm{~mL}$ with methanol. The absorbance of the supernatant was measured in a spectrophotometer at $485 \mathrm{~nm}$. The results were expressed as $\mu \mathrm{g}$ TPF $\mathrm{g}^{-1}$ dry soil. 
214 The microbial community composition of the soil samples was determined using PLFA

215 analysis, as described in Pose-Juan et al. (2015a). Briefly, samples were freeze-dried,

216 and 2 g of dry material was used for lipid extraction. Lipids were extracted with a one-

217 phase chloroform-methanol-phosphate buffer solvent. Phospholipids were separated

218 from non-polar lipids and converted to fatty acid methyl esters before analysis.

219 Quantification was performed using an Agilent 7890 gas chromatograph (Agilent

220 Technologies, Wilmington, DE, USA) equipped with a 25-m Ultra 2 (5\% phenyl)-

221 methylpolysiloxane column (J\&W Scientific, Folsom, CA, USA) and a flame ionization

222 detector. PLFAs were identified using bacterial fatty acid standards and software from

223 the Microbial Identification System (Microbial ID, Inc., Newark, DE, USA)

2242.6 Statistical analysis

225 Data were analyzed by one-way analysis of variance (ANOVA) being the main factors soil treatments and sampling times. Duncan or Games-Howell post-hoc test (according

227 to Levene variance homogeneity test) at $p<0.05$ was used to determine significant

228 differences between means and evaluate the effects of the different soil treatments at the same sampling time and the sampling times within the same soil treatment on the microbial biomass, respiration, DHA and PLFAs of soils. Pearson correlation coefficients between the remaining percentages of herbicides, soil OC, and microbial structure and activity were determined to elucidate how variables are related to each other. ANOVA and correlation analyses were carried out using the IBM SPSS Statistics v24 software package. Finally, principal component analysis (PCA) was performed, with PAST v3.15 software (Hammer et al., 2001), to determine the most meaningful variables and the global impact of the herbicides and GC on soil microbial communities. 


\section{Results and discussion}

239

240

241

242

243

244

245

246

247

248

249

250

251

252

253

254

255

256

257

258

259

260

261

\subsection{Dissipation of herbicides}

Table 1 shows the remaining percentages of TSF and PSC at 30 and 100 days after the application of individual or combined herbicide formulations. The concentrations measured at the beginning of the dissipation study ranged between $0.073-0.211 \mathrm{mg}$ TSF $\mathrm{kg}^{-1}$ dry soil and 4.56-5.22 mg PSC $\mathrm{kg}^{-1}$ dry soil, respectively, in different plots. At 30 days after herbicide application, the remaining percentages of TSF and PSC were between $29 \%$ and $62 \%$ and between $20 \%$ and $37 \%$ of the initial concentrations, respectively, for the different conditions studied. At 100 days after herbicide application, there was almost no further dissipation of either TSF or PSC, with the remaining percentages of TSF and PSC being between $2.2 \%$ and $9.4 \%$ and $0.4 \%$ and $2.1 \%$, respectively. PSC therefore recorded a higher dissipation rate than TSF under the different conditions assayed.

The GC-amended soil recorded slower TSF dissipation than the unamended soil. However, the dissipation of PSC was not affected by GC application. Pose-Juan et al. (2017) described the decrease of TSF dissipation in the soil amended with GC compared to the unamended soil at laboratory scale. The decrease in TSF dissipation in Soil+GC could be due to a decrease in microbial degradation caused by herbicide adsorption by soil organic matter. Adsorption reduces pesticide solubility in a soil solution and its bioavailability to microbial degradation, increasing the presence of pesticides in the top soil (Herrero-Hernández et al., 2015; Marín-Benito et al., 2013). In contrast, the fact there were no differences for PSC dissipation between the GCamended and unamended soils could be due to two factors: firstly, this compound's high hydrophobicity (low water solubility, Table S1) may lead to high adsorption in 
262 both the GC-amended and unamended soils; secondly, the possible losses by 263 volatilization of the parent compound (Braun et al., 2017). A detailed description of the 264 dissipation kinetics and mechanisms of TSF and PSC in the GC-amended and 265 unamended soils has been reported in Marín-Benito et al. (2018).

3.2 Soil microbial biomass and activity

\subsubsection{Soil microbial biomass}

268

269

270

271

272

273

Fig. 1 shows the evolution of C-microbial biomass in the unamended and GC-amended soils either untreated or treated with herbicides. No significant differences were detected in the microbial biomass in the control soil (Soil) between sampling times with the mass remaining constant during the assay. At short and medium time ( $0-30$ days), the individual application of the herbicides TSF and PSC in the unamended soil did not modify the microbial biomass compared to the control treatment. However, 100 days after herbicide application the biomass increased in the presence of TSF and/or PSC in the unamended soil, with the combination of TSF+PSC producing a significant increase $(p<0.05)$ in microbial biomass compared to the control soil and the soil treated individually with TSF or PSC.

Toxic effects of TFS and other sulfonylurea herbicides were reported at laboratory scale for field or higher doses after 30 days of incubation (Sofo et al., 2012). In this work a certain toxicity of TSF was observed in Soil+TSF after 30 days. Biomass decreased (Fig. 1) compared to initial time, although at the end of the assay the microbial biomass in Soil+TSF and Soil+TSF+PSC increased to values similar to those at the beginning of the assay. This means the toxic effects of TSF were limited in time, and the microbial biomass recovered with TSF dissipation. Lupwayi et al. (2004) have not reported any 
significant effects of a field dose of TSF on C-microbial biomass at field scale. Similarly, in a field experiment, butachlor applied at the recommended dose had not significant effect on C-microbial biomass (Singh et al., 2016). On the contrary, the twoyear application of the herbicide imazethapyr to soybean fields increased the $\mathrm{C}$ microbial biomass indicating that the herbicide itself might provide a carbon source for soil microorganisms (Zhang et al., 2010).

The application of GC to soil enhanced the microbial biomass over that of the unamended soil from the beginning of the assay, with the detection of significant differences between sampling times (Fig. 1). The increase in microbial biomass after GC application has already been reported in herbicide dissipation studies at laboratory scale (Pose-Juan et al., 2017, 2015a, 2015c) or for other organic amendments at field scale (Singh et al., 2016). Neither did the individual application of herbicides modify the increased microbial biomass observed in the Soil+GC over the short and medium term (0 - 30 days $)$ as in the unamended soil. Soil+GC buffered the effects of these herbicides, and significant differences were observed solely in the evolution of each treatment at 100 days after herbicide application. At this time in contrast to the unamended soil, TSF applied individually (Soil+GC+TSF) or in combination with PSC $($ Soil+GC+TSF+PSC) led to a decrease $(p<0.05)$ in microbial biomass with respect to Soil+GC especially in combination with PSC. With respect to initial values, microbial biomass in Soil+GC treatments tends to increase at the end of the assay, except in Soil+GC+TSF+PSC, where the microbial biomass did not record any significant differences between the initial and final sampling times, which confirms the negative effect of the combined application of both herbicides, TSF and PSC. These effects could be due to the higher amounts of herbicides remaining at 100 days in Soil+GC (Table 1) compared to unamended soil, which may have a toxic effect on the microbial biomass. 
Pose-Juan et al. (2017) have reported an increase of microbial biomass at a low dose of

TSF in a soil amended with GC during the incubation period. The general reduction in microbial biomass at 30 days in all the treatments could be due to external factors such as weather conditions or low moisture in the surface soil (Marín-Benito et al., 2018).

\subsubsection{Soil respiration}

315

316

317

318

319

320

321

322

Fig. 2 presents the soil respiration results, expressed as $\mathrm{mg}$ of $\mathrm{O}_{2}$ consumed per $\mathrm{kg}$ of dry soil. Soil respiration was very sensitive to treatments and sampling times. Respiration of the unamended soil decreased at initial time, and at 30 days after TSF was applied individually or combined with PSC (Soil+TSF and Soil+TSF+PSC). However the individual application of PSC (Soil+PSC) did not record any significant decreasing effect $(p>0.05)$ regarding the Soil control. Sofo et al. (2012) have also described the inhibition of soil respiration over 30 days of TSF application, although other sulfonylureas either promoted or had no effect on soil respiration at 30 days of incubation. Finally, at 100 days after herbicide application, respiration in soils Soil+TSF, Soil+PSC, and Soil+TSF+PSC was higher $(p<0.05)$ than at 0 or 30 days. This is in agreement with the increase in microbial biomass (Fig. 1), but soil respiration in presence of herbicides was reduced compared to the Soil control $(p<0.05)$ in spite of the remaining amounts of herbicide at this time were low. Similarly, the application of the herbicide fomesafen at the field dose resulted in significantly lower basal respiration rates during the first 15 days, whereas it was significantly lower at all incubation times in soil treated with higher doses of herbicide (Wu et al., 2014).

The addition of GC enhanced soil respiration with respect to the unamended soil ( $\mathrm{p}<$ 0.05), and initially buffered the effect of the individual application of TSF (Soil+GC+TSF), which did not modify the respiration with respect to the Soil+GC 
control. However, the buffer capacity of GC was ineffective for the combined application of TSF and PSC (Soil+GC+TSF+PSC), which reduced soil respiration to the values of the unamended soil (Soil+TSF and Soil+TSF+PSC). At 30 days after herbicide application, respiration also tended to decrease in the soils treated with TSF (Soil+GC+TSF), but soils treated with PSC recorded significant increase compared with the Soil+GC control. Prosulfocarb increased soil respiration as it was reported in other laboratory experiments in GC amended soil in the presence of TSF (Pose-Juan et al., 2017) or high doses of mesotrione (Pose-Juan et al., 2015c). An increase of respiration was observed at 100 days after herbicide application in GC amended soils $(p<0.05)$, but soil respiration was reduced in Soil+GC+PSC and Soil+GC+TSF+PSC compared to the Soil+GC control $(p<0.05)$ as it was observed in unamended soils.

\subsubsection{Soil dehydrogenase activity (DHA)}

346

Fig. 3 presents the DHA values for the unamended and GC-amended soils either untreated or treated with herbicides. The DHA values were not affected by GC or herbicide application at 0 and 30 days of assay. At 100 days, there were no significant differences between the control soil (Soil) and the soil treated with herbicides (Soil+TSF, Soil+PSC and Soil+TSF+PSC). The DHA in Soil was constant over the 100 days of assay; in contrast, the DHA values decreased over time for treatments Soil+TSF, Soil+PSC, Soil+TSF+PSC $(p<0.05)$, reflecting the impact of herbicides or their metabolites on microbial activity. However, the herbicide napropamide applied at field rates had a negative impact on DHA at the beginning of the experiment (Cycon et al., 2013).

DHA values also decreased in Soil+GC over time. A similar trend has been observed in a previous study using soil amended with GC at laboratory scale (Pose-Juan et al., 
2015a). The soil microbiota retained their functional activity despite the sampling time and the individual or combined application of herbicides in Soil+GC. The DHA values increased significantly at 100 days in Soil+GC+PSC $(p<0.05)$. However, the DHA values were constant in Soil+GC+TSF and Soil+GC+TSF+PSC treatments over the assay period, being similar or higher than the DHA values in the Soil+GC control. The application of GC therefore buffered the negative effects of TSF and PSC in soil DHA over time. A similar conclusion has been reported for the herbicide oxyfluorfen, which recorded a lower inhibition of enzymatic activities, including DHA, when organic wastes were added to soils (Gómez et al., 2014).

\subsection{Phospholipid fatty acids profile analysis}

Fig. 4 shows the relative abundance of PLFAs that specifically diagnose Gram-negative and Gram-positive bacteria, Actinobacteria, and fungi at seven days before herbicide application, and at 0,30 and 100 days after herbicide application in the unamended and GC-amended soils.

Previously to application of herbicides the relative abundance of PLFAs in the plots of unamended soil and in the plots of GC-amended soil was analyzed. The results revealed no significant differences in the relative abundance of Gram-positive and Gramnegative bacteria, Actinobacteria, and fungi between plots of unamended soil or between plots of amended soil. Consequently a homogeneous microbial structure was recorded for Soil plots and for Soil+GC plots respectively. However, the comparison of microbial structure of Soil plots with Soil+GC plots indicated the application of GC to soil decreased $(p<0.05)$ the abundance of fungi with respect to the unamended soil (Fig. 4). This shift in the soil microbial structure immediately after GC addition (and 
381 previous herbicide application) was due to the input of new microorganisms from the compost's inherent microbial population (García-Delgado et al., 2015).

383

At 0 days of herbicide application, no significant differences were observed between Soil or Soil+GC controls and these soils treated with TSF, PSC or TSF+PSC. This means there was no modification of the microbial structure immediately after individual (TSF or PSC) or combined (TSF+PSC) herbicide application. Neither did a previous work on TSF dissipation at laboratory scale report any significant changes in unamended and GC-amended soils even at a very high concentration (50 mg kg-1) immediately after herbicide application (Pose-Juan et al., 2017). However, other herbicides such as napropamide, acetochlor or MCPA significantly shifted the microbial community structure at the beginning of the incubation (Bai et al., 2013; Cycon et al., 2013; Saleh et al., 2016).

At 30 days after herbicide application in the unamended soil a significantly higher abundance of fungi was detected in Soil+TSF+PSC compared to the Soil control or Soil+TSF and Soil+PSC $(p<0.05)$. This higher abundance of fungi was offset by a decrease in Gram-positive bacteria and no changes were detected in Gram-negative bacteria or Actinobacteria. By contrast in Soil+GC, the combined application of TSF+PSC increased the abundance of Gram-positive bacteria $(p<0.05)$ and the application of individual TSF led to a decrease in fungi $(p<0.05)$. The relative abundance of Actinobacteria and Gram-positive bacteria were higher in Soil+GC+TSF and Soil+GC+TSF+PSC than in their respective treatments in the unamended soil $(p<$ 0.05), but there was a lower abundance of fungi in Soil+GC+TSF+PSC than in Soil+TSF+PSC $(p<0.05)$. 
404 At 100 days, there were significant differences $(p<0.05)$ between the treatments for 405 Gram-negative and Gram-positive bacteria and Actinobacteria, but not for fungi. The 406 lack of significant differences for fungi could be because fungi belong to the group of 407 microorganisms that after an initial sensitive response to the presence of pesticides in 408 the soil rapidly establish a normal metabolism (Kalia and Gosal, 2011). Overall, 409 herbicides do not have a negative impact on the soil fungal population when applied at 410 the recommended doses (Kalia and Gosal, 2011). At this time (100 days) the 411 simultaneous application of TSF+PSC in the unamended soil, led to a significant 412 increase in the relative abundance of Gram-positive bacteria and a decrease in Gram413 negative bacteria $(p<0.05)$ compared to Soil and Soil+TSF or Soil+PSC. This means 414 that only the combined application of both herbicides modified bacterial diversity, and no significant shift was detected in the soils treated individually with TSF or PSC. This effect was buffered in the GC-amended soil, and no significant differences were found in the relative abundance of Gram-positive and Gram-negative bacteria. In contrast, the relative abundance of Actinobacteria increased $(p<0.05)$ in Soil+GC treated with 419 individual or combined herbicides. Cycoń et al. (2012) found an increased amount of bacterial and fungal PLFAs in a soil after application of teflubenzuron at the end of the incubation time possibly due to the utilization of insecticide by soil microorganisms.

The ratio Gram-positive/Gram-negative bacteria (Fig. 5) decreased significantly over time for all the treatments $(p<0.05)$, except for Soil+GC+TSF, which did not record any significant differences. At 100 days after herbicide application, the ratio Grampositive/Gram-negative bacteria was significantly higher $(p<0.05)$ in Soil+TSF+PSC than in Soil and Soil+TSF or Soil+PSC. However, no significant differences were found between treatments in the GC-amended soils. Therefore, GC was able to buffer the microbial shift produced by the combined application of TSF+PSC. Pose-Juan et al. 
429 (2015a) have described a shift in the bacteria ratio towards Gram-negative bacteria in 430 the Soil+GC soil over 98 days of incubation. They have reported that both the overall 431 structure of active microbial communities and the relative abundance of certain groups 432 of microorganisms clearly change according to the type of amendment and the time of 433 incubation, but remain unaffected by the application of the herbicide mesotrione.

434 A statistical analysis of each microbial group's trend over time in untreated soils and 435 those treated with herbicides showed a clear shift in microbial diversity. During the assay, there was an increase in the relative abundance of Gram-negative bacteria and Actinobacteria in the unamended and GC-amended soils, whereas the relative abundance of Gram-positive bacteria decreased, and the percentage of fungi remained almost the same (Fig. 4 and Fig. 5). It has been observed that Gram-negative bacteria can multiply rapidly in the presence of additional carbon sources (Cycoń et al., 2012) and fungi are more sensitive to chemical stresses (Wu et al., 2014). Similarly, Zhang et al. (2010) reported an increase in Gram-negative bacteria by the application of the herbicide imazethapyr for two years in a soybean field suggesting the herbicide may act as a carbon source. However, in a field study, application of nicosulfuron at agronomical rate did not significantly affect the abundance of fungi and bacteria, and did not induce large alterations in the soil microbial structure (Karpouzas et al., 2014).

Table 2 shows the Pearson correlation coefficients between the percentage of remaining herbicides, soil OC, and microbial structure and activity, and Fig. 6 presents the principal component analysis (PCA) of these variables. The combination of both analyses shows how some variables are related to each other. The relative percentage of 452 Gram-positive bacteria negatively correlates with the relative percentage of Gram- 
negative bacteria and Actinobacteria (Table 2). This is clearly shown in the loading

454 factors of PCA (Fig. 6), where Gram-positive bacteria and Gram-negative bacteria and Actinobacteria are opposite and strongly related to PC1. Significant positive correlations are found between microbial biomass and soil respiration, microbial biomass and $\mathrm{OC}$ and DHA and OC, suggesting that microbial biomass and activity and soil OC are interrelated. This has been confirmed with the PCA, where all these variables are positively related to PC2 (Fig 6). Organic amendments have a positive effect on soil microbial biomass and DHA because organic amendments are the carriers of new microbial populations, and the input of new available OC stimulates microbial activity (Álvarez-Martín et al., 2016a; García-Delgado et al., 2015; Pose-Juan et al., 2015c).

The scores for each treatment and sampling time on the PCA (Fig 6) show the different evolution of each treatment during the field assay. At 0 days after herbicide application, all the treatments were in the negative zone of PC1, positively related to Gram-positive bacteria and herbicides, and poorly related to Gram-negative bacteria, Actinobacteria, and the evolution of time. The unamended soils were in the negative zone of PC2. The unamended soils were therefore less related to soil OC, microbial biomass, soil respiration and DHA than the GC-amended soils. The application of herbicides had no major impact because of these treatments' low shift in PC2. The individual or combined

472 application of TSF and PSC in the GC-amended soils had a low impact in PC1, albeit 473 with a clear decrease in PC2 scores compared to the Soil+GC control soil.

474 At 30 days after herbicide application, the unamended and GC-amended soils, untreated and treated with herbicides, recorded a similar shift to the positive zone of PC1, indicating herbicide dissipation, and a shift to Gram-negative bacteria and 
Actinobacteria. The unamended and GC-amended soils decreased their scores in PC2.

478 This evolution indicated a decrease in soil microbial biomass and activity. However, both soils continued to record differences in PC2, where the unamended soils had lower scores. The presence of TSF, PSC, or a combination thereof, did not record a major shift from the control treatments (Soil and Soil+GC), so the impact of these herbicides after 30 days did not have a significant overall impact on microbial structure and activity.

At 100 days after herbicide application, the unamended and GC-amended soils presented a clear difference in the PCA analysis. The unamended soils (Soil, Soil+PSC and Soil+TSF) recorded a higher score in PC1 than the GC-amended soil. In contrast, the combination of herbicides in the unamended soil (Soil+TSF+PSC) recorded a similar value for the PC1 score as the GC-amended soils. Therefore, treatments Soil, Soil+PSC and Soil+TSF were more closely related to a high proportion of Gramnegative bacteria and Actinobacteria and low microbial biomass and activity than the combined herbicide treatment in Soil and Soil+GC. This means that the combination of TSF and PSC in the unamended soil changed the microbial structure compared to the individual application of these herbicides or to no application at all. However, the individual application of TSF or PSC did not produce a major shift in the microbial structure compared to the untreated soil (PC1). The relative low distance of unamended soils (Soil, Soil+TSF, Soil+PSC and Soil+TSF+PSC) along PC2 denotes low impact of these herbicides on soil microbial biomass and activity at the end of the assay. In the case of the GC-amended soils, the application of TSF or PSC impacted on PC2, related to microbial biomass and activity but not on PC1, related with the microbial structure. Soil+GC+PSC is very close to Soil+GC, indicating a similar evolution (Fig. 6B) and therefore low impact of PSC in the microbial activity on GC-amended soil. In contrast, the application of TSF (Soil+GC+TSF), and moreover the combined application of TSF 
and PSC (Soil+GC+TSF+PSC), clearly decreased the score of PC2 with respect to Soil+GC and Soil+GC+PSC, indicating negative impact on microbial activity. The application of TSF and the combination of TSF and PSC therefore impacted negatively on microbial biomass and activity at 100 days in GC-amended soil. Prosulfocarb's lower impact than TSF on soil microbial structure and activity could be related to the former's higher hydrophobicity (Table SI 1) and faster dissipation (Table 1), as well as to its volatile nature (Braun et al., 2017; Nunes et al., 2013), which minimized PSC availability to soil microorganisms.

Therefore, at the end of the assay, combination of TSF and PSC in unamended soil produced a shift of the microbial structure while individual application of TSF or combination of TSF and PSC in GC-amended soil produced negative effects on microbial biomass and activity but not microbial structure shift.

\section{Conclusions}

The simultaneous application of GC as an organic amendment and the herbicides TSF and PSC in an agricultural soil at field scale impacted on soil microbial activity and structure. The sulfonylurea herbicide TSF recorded a higher impact than the thiocarbamate herbicide PSC on soil microbial biomass and respiration. The combined application of TSF and PSC in an unamended soil produced a shift in the soil microbial structure. GC is useful for buffering the effects of herbicides on soil microbial biomass and activity, and reduces the shift in the soil microbial structure. However, despite the buffer effect of GC on microbial community towards herbicides, the combined application of TSF and PSC in GC-amended soil produced changes in soil microbial abundance and activity compared to the application of these herbicides individually or to no application at all. The use of GC is therefore recommended to minimize the 
526 impact of herbicides on soil microbiota, and furthermore reduce the risk of pollution by

527 herbicide leaching. Finally, additional studies are also needed to evaluate the impact of 528 additives (solvents and surfactants) present in commercial formulations of pesticides on

529 the soil microbial communities. The possible negative effects of these compounds in 530 pesticide formulations need to be evaluated according with the EU regulation 531 (EC1107/2009) concerning the introduction of plant protection products on the market.

\section{Acknowledgments}

533 This work was financially supported by the "Junta de Castilla y León" (project 534 CSI240U14). J.M. Marín-Benito and C. García-Delgado thank Ministry of Economy 535 and Competitiveness for their respective "Juan de la Cierva-Incorporación" and "Juan 536 de la Cierva-Formación" postdoctoral contracts (IJCI-2014-19538 and JCFI-2015537 23543). V. Barba thanks "Junta de Castilla y León” for his predoctoral contract.

\section{$538 \quad$ References}

539 Álvarez-Martín, A., Hilton, S.L., Bending, G.D., Rodríguez-Cruz, M.S., Sánchez540 Martín, M.J., 2016a. Changes in activity and structure of the soil microbial community 541 after application of azoxystrobin or pirimicarb and an organic amendment to an 542 agricultural soil. Appl. Soil Ecol. 106, 47-57. doi:10.1016/j.apsoil.2016.05.005

543 Álvarez-Martín, A., Rodríguez-Cruz, M.S., Andrades, M.S., Sánchez-Martín, M.J., 544 2016b. Application of a biosorbent to soil: a potential method for controlling water 545 pollution by pesticides. Environ. Sci. Pollut. Res. 23, 9192-9203. doi:10.1007/s11356016-6132-4 
547 Bai, Z., Xu, H.J., He, H.B., Zheng, L.C., Zhang, X.D. 2013. Alterations of microbial 548 populations and composition in the rizosphere and bultk soil as affected by residual 549 acetochlor. Environ. Sci. Pollut. Res. 20, 369-379. doi: 10.1007/s11356-012-1061-3

550 Braun, K.E., Luks, A.-K., Schmidt, B., 2017. Fate of the 14 C-labeled herbicide 551 prosulfocarb in a soil and in a sediment-water system. J. Environ. Sci. Health. B. 52, 552 122-130. doi:10.1080/03601234.2016.1248140

553 Clemente, R., Pardo, T., Madejón, P., Madejón, E., Bernal, M.P., 2015. Food 554 byproducts as amendments in trace elements contaminated soils. Food Res. Int. 73, 555 176-189. doi:10.1016/j.foodres.2015.03.040

556 Cycoń, M., Wójcik, M., Borymski, S., Piotrowska-Seget, Z. 2012. A broad-spectrum 557 analysis of the effects of teflubenzuron exposure on the biochemical activities and 558 microbial community structure of soil. J. Environ. Manage. 108, 27-35. 559 doi:10.1016/j.jenvman.2012.05.002

560 Cycoń, M., Wójcik, M., Borymski, S., Piotrowska-Seget, Z. 2013. Short-term effects of 561 the herbicide napropamide on the activity and structure of the soil microbial community 562 assessed by the multiapproach analysis. Appl. Soil Ecol. 66, 8-18. 563 doi:10.1016/j.apsoil.2013.01.014

564 EFSA (European Food Safety Authority), 2007. Conclusion on the peer review of 565 prosulfocarb. Scientific Report 111, 1-81.

566 EFSA (European Food Safety Authority), 2015. Conclusion on the peer review of the 567 pesticide risk assessment of the active substance triasulfuron. EFSA Journal 13, 3958, 568 78pp. 
569 García-Delgado, C., D’Annibale, A., Pesciaroli, L., Yunta, F., Crognale, S., Petruccioli, 570 M., Eymar, E., 2015. Implications of polluted soil biostimulation and bioaugmentation 571 with spent mushroom substrate (Agaricus bisporus) on the microbial community and

572 polycyclic aromatic hydrocarbons biodegradation. Sci. Total Environ. 508, 20-28. 573 doi:10.1016/j.scitotenv.2014.11.046

574 García-Izquierdo, C. 2003. Técnicas de análisis de parámetros bioquímicos en suelos: 575 medida de actividades enzimáticas y biomasa microbiana. Mundi-Prensa, Madrid .

576 Gennari, M., Ambrosoli, R., Nègre, M., Minati, J.L., 2002. Bioavailability and 577 biodegradation of prosulfocarb in soil. J. Environ. Sci. Health B 37, 297-305. 578 doi:10.1081/PFC-120004471

579 Gómez, I., Rodríguez-Morgado, B., Parrado, J., García, C., Hernández, T., Tejada, M., 580 2014. Behavior of oxyfluorfen in soils amended with different sources of organic 581 matter. Effects on soil biology. J. Hazard. Mater. 273, 207-214. 582 doi:10.1016/j.jhazmat.2014.03.051

583 Hammer, Ø., Harper, D.A.T., and P. D. Ryan, 2001. PAST: Paleontological Statistics 584 Software Package for Education and Data Analysis. Palaeontologia Electronica 4, 9-18.

585 Herrero-Hernández, E., Marín-Benito, J.M., Andrades, M.S., Sánchez-Martín, M.J., 586 Rodríguez-Cruz, M.S., 2015. Field versus laboratory experiments to evaluate the fate of 587 azoxystrobin in an amended vineyard soil. J. Environ Manage. 163, 78-86. 588 doi:10.1016/j.jenvman.2015.08.010

589 Herrero-Hernández, E., Pose-Juan, E., Sánchez-Martín, M.J., Andrades, M.S., 590 Rodríguez-Cruz, M.S., 2016. Intra-annual trends of fungicide residues in waters from 
591 vineyard areas in La Rioja region of northern Spain. Environ. Sci. Pollut. Res. 23, 22924-22936. doi:10.1007/s11356-016-7497-0

593 Hjorth, M., Mathiassen, S.K., Kudsk, P., Ravn, H.W., 2006. Amino acids in loose silky594 bent (Apera spica-venti (L.) Beauv.) responding to prosulfocarb exposure and the 595 correlation with physiological effects. Pestic. Biochem. Physiol. 86, 138-145. 596 doi:10.1016/j.pestbp.2006.02.006

597 Huang, X., He, J., Yan, X., Hong, Q., Chen, K., He, Q., Zhang, L., Liu, X., Chuang, S., 598 Li, S., Jiang, J., 2016. Microbial catabolism of chemical herbicides: Microbial 599 resources, metabolic pathways and catabolic genes. Pestic. Biochem. Physiol. 600 doi:10.1016/j.pestbp.2016.11.010

601 Hussain, S., Arshad, M., Springael, D., SøRensen, S.R., Bending, G.D., Devers602 Lamrani, M., Maqbool, Z., Martin-Laurent, F., 2015. Abiotic and biotic processes 603 governing the fate of phenylurea herbicides in soils: A review. Crit. Rev. Environ. Sci. 604 Technol. 45, 1947-1998. doi:10.1080/10643389.2014.1001141

605 Hussain, S., Siddique, T., Arshad, M., Saleem, M., 2009. Bioremediation and 606 phytoremediation of pesticides: Recent advances. Crit. Rev. Environ. Sci. Technol. 39, 607 843-907. doi:10.1080/10643380801910090

608 Imfeld, G., Vuilleumier, S., 2012. Measuring the effects of pesticides on bacterial 609 communities in soil: A critical review. Eur. J. Soil Biol. 49, 22-30. 610 doi:10.1016/j.ejsobi.2011.11.010

611 Kalia, A., Gosal, S.K., 2011. Effect of pesticide application on soil microorganisms. 612 Arch. Agron. Soil Sci. 57, 569-596. doi:10.1080/03650341003787582 
613 Karpouzas, D.G., Kandeler, E., Bru, D., Friedel, I., Auer, Y., Kramer, S., Vasileiadis, 614 S., Petric, I., Udikovic-Kolic, N., Djuric, S., Martin-Laurent, F., 2014. A tiered 615 assessment approach based on standardized methods to estimate the impact of 616 nicosulfuron on the abundance and function of the soil microbial community. Soil Biol. 617 Biochem. 75, 282-291. doi:10.1016/j.soilbio.2014.04.022

618 López-Rayo, S., Laursen, K.H., Lekfeldt, J.D.S., Grazie, F.D., Magid, J., 2016. Long619 term amendment of urban and animal wastes equivalent to more than 100 years of 620 application had minimal effect on plant uptake of potentially toxic elements. Agric. 621 Ecosyst. Environ. 231, 44-53. doi:10.1016/j.agee.2016.06.019

622 Lupwayi, N.Z., Harker, K.N., Clayton, G.W., Turkington, T.K., Rice, W.A., 623 O'Donovan, J.T., 2004. Soil microbial biomass and diversity after herbicide application. 624 Can. J. Plant Sci. 84, 677-685. doi:10.4141/P03-121 Marín-Benito, J.M., Andrades, M.S., Sánchez-Martín, M.J., Rodríguez-Cruz, M.S., 2012. Dissipation of fungicides in a vineyard soil amended with different spent mushroom substrates. J. Agric. Food Chem. 60, 6936-45. doi:10.1021/jf301322h

Marín-Benito, J.M., Barba, V., Ordax, J.M., Andrades, M.S., Sánchez-Martín, M.J., Rodríguez-Cruz M.S. 2018. Application of green compost as amendment in an agricultural soil: Effect on the behaviour of triasulfuron and prosulfocarb under field conditions. J. Environ. Manage. 207, 180-191.

Marín-Benito, J.M., Brown, C.D., Herrero-Hernández, E., Arienzo, M., SánchezMartín, M.J., Rodríguez-Cruz, M.S., 2013. Use of raw or incubated organic wastes as amendments in reducing pesticide leaching through soil columns. Sci. Total Environ. 463-464, 589-599. doi:10.1016/j.scitotenv.2013.06.051 
636

637

638

639

640

641

642

643

644

645

646

647

648

649

650

651

652

653

654

655

656

657

Marín-Benito, J.M., Herrero-Hernández, E., Andrades, M.S., Sánchez-Martín, M.J., Rodríguez-Cruz, M.S., 2014. Effect of different organic amendments on the dissipation of linuron, diazinon and myclobutanil in an agricultural soil incubated for different time periods. Sci. Total Environ. 476-477, 611-621. doi:10.1016/j.scitotenv.2014.01.052

Marín-Benito, J.M., Herrero-Hernández, E., Rodríguez-Cruz, M.S., Arienzo, M., Sánchez-Martín, M.J., 2017. Study of processes influencing bioavailability of pesticides in wood-soil systems: Effect of different factors. Ecotoxicol. Environ. Saf. 139, 454462. doi:10.1016/j.ecoenv.2017.02.012

Martin-Laurent, F., Benizri, E., Durand, R., Gianinazzi-Pearson, V., Guilbaut, P., Lauga, B., Leyval, C., Philippot, L., Riveira-Becceril, F., Salducci, X., Soulas, G. 2010. Bioindicators for the assessment of side effects of pesticides on soil biological status: Report of a collaborative study conducted for the French ministry of the environment. In: Bufo, S.A., Scrano, L. (Eds.), Pesticides 2010, $6^{\text {th }}$ European Conference on Pesticides and Related Organic Micropollutants in the Environment, University of Basilicata, Potenza, Italy, p. 231-236.

Medina, E., Paredes, C., Bustamante, M.A., Moral, R., Moreno-Caselles, J., 2012. Relationships between soil physico-chemical, chemical and biological properties in a soil amended with spent mushroom substrate. Geoderma 173-174, 152-161. doi:10.1016/j.geoderma.2011.12.011

Medina, J., Monreal, C., Barea, J.M., Arriagada, C., Borie, F., Cornejo, P., 2015. Crop residue stabilization and application to agricultural and degraded soils: A review. Waste Manag. 42, 41-54. doi:10.1016/j.wasman.2015.04.002 
658

659

660

661

662

663

664

665

666

667

668

669

670

671

672

673

674

675

676

677

678

Nègre, M., Passarella, I., Boursier, C., Mozzetti, C., Gennari, M., 2006. Evaluation of the bioavailability of the herbicide prosulfocarb through adsorption on soils and model colloids, and through a simple bioassay. Pest Manag. Sci. 62, 957-964. doi: $10.1002 /$ ps. 1264

Nunes, O.C., Lopes, A.R., Manaia, C.M., 2013. Microbial degradation of the herbicide molinate by defined cultures and in the environment. Appl. Microbiol. Biotechnol. 97, 10275-10291. doi:10.1007/s00253-013-5316-9

Odukkathil, G., Vasudevan, N., 2013. Toxicity and bioremediation of pesticides in agricultural soil. Rev. Environ. Sci. Biotechnol. 12, 421-444. doi:10.1007/s11157-0139320-4

Patyka, V., Buletsa, N., Pasichnyk, L., Zhitkevich, N., Kalinichenko, A., Gnatiuk, T., Butsenko, L., 2016. Specifics of pesticides effects on the phytopathogenic bacteria. Ecol. Chem. Eng. S 23, 311-331. doi:10.1515/eces-2016-0022

Petric, I., Karpouzas, D.G., Bru, D., Udikovic-Kolic, N., Kandeler, E., Djuric, S., Martin-Laurent, F., 2016. Nicosulfuron application in agricultural soils drives the selection towards NS-tolerant microorganisms harboring various levels of sensitivity to nicosulfuron. Environ. Sci. Poll. Res. 23, 4320-4333. doi:10.1007/s11356-015-5645-6

Pose-Juan, E., Igual, J.M., Curto, N., Sánchez-Martín, M.J., Rodríguez-Cruz, M.S., 2015a. Mesotrione dissipation and response of soil microbial communities in a soil amended with organic residues. Spanish J. Soil Sci. 5, 12-25. doi:10.3232/SJSS.2015.V5.N1.02 
679 Pose-Juan, E., Igual, J.M., Sánchez-Martín, M.J., Rodríguez-Cruz, M.S., 2017.

680 Influence of herbicide triasulfuron on soil microbial community in an unamended soil 681 and a soil amended with organic residues. Front. Microbiol, 8, 378. 682 doi:10.3389/fmicb.2017.00378

683 Pose-Juan, E., Sánchez-Martín, M.J., Andrades, M.S., Rodríguez-Cruz, M.S., Herrero684 Hernández, E., 2015b. Pesticide residues in vineyard soils from Spain: Spatial and 685 temporal distributions. Sci. Total Environ. 514, 351-358. 686 doi:10.1016/j.scitotenv.2015.01.076

687 Pose-Juan, E., Sánchez-Martín, M.J., Herrero-Hernández, E., Rodríguez-Cruz, M.S., 688 2015c. Application of mesotrione at different doses in an amended soil: Dissipation and 689 effect on the soil microbial biomass and activity. Sci. Total Environ. 536, 31-38. 690 doi:10.1016/j.scitotenv.2015.07.039

691 PPDB, Pesticide Properties Database, 2017. Agriculture \& Environment Research Unit 692 (AERU). University of Hertfordshire. http://sitem.herts.ac.uk/aeru/ppdb/en/ (accessed 693 July 2017)

694 Said-Pullicino, D., Gigliotti, G., Vella, A.J., 2004. Environmental fate of triasulfuron in 695 soils amended with municipal waste compost. J. Environ. Qual. 33, 1743-1751.

696 Saleh, O., Pagel, H., Enowashu, E., Devers, M., Martin-Laurent, F., Streck, T., 697 Kandeler, E., Poll, C., 2016. Evidence for the importance of litter as co-substrate for 698 MCPA dissipation in an agricultural soil. Environ. Sci. Pollut. Res. 23, 4164-4175. doi: 699 10.1007/s11356-015-4633-1 
700 Sánchez-González, S., Pose-Juan, E., Herrero-Hernández, E., Álvarez-Martín, A., 701 Sánchez-Martín, M.J., Rodríguez-Cruz, S., 2013. Pesticide residues in groundwaters 702 and soils of agricultural areas in the Águeda River Basin from Spain and Portugal. Int. 703 J. Environ. Anal. Chem. 93, 1585-1601. doi:10.1080/03067319.2013.814122

704 Singh, S.B., Kulshrestha, G., 2006. Soil persistence of triasulfuron herbicide as affected 705 by biotic and abiotic factors. J. Environ. Sci. Health B 41, 635-645. doi: 706 $10.1080 / 03601230600701791$

707

Singh, A., Singh, M.K., Ghoshal, N., 2016. Microbial biomass dynamics in a tropical 708 agroecosystem: Influence of herbicide and soil amendments. Pedosphere 26, 257-264. doi:10.1016/S1002-0160(15)60040-6

Singh, B.K., Walker, A., Wright, D.J., 2002. Degradation of chlorpyrifos, fenamiphos, and chlorothalonil alone and in combination and their effects on soil microbial activity. Environ. Toxicol. Chem. 21, 2600-2605. doi:10.1016/S1001-0742(08)62080-X

Sofo, A., Scopa, A., Dumontet, S., Mazzatura, A., Pasquale, V., 2012. Toxic effects of 714 four sulphonylureas herbicides on soil microbial biomass. J. Environ. Sci. Heal. Part B. 715 47, 653-659. doi:10.1080/03601234.2012.669205

717 Conservation Service, Washington, DC.

718 Spyrou, I.M., Karpouzas, D.G., Menkissoglu-Spiroudi, U., 2009. Do botanical 719 pesticides alter the structure of the soil microbial community? Microb. Ecol. 58, 715720 727. doi:10.1007/s00248-009-9522-z 
721 Sun, D., Li, K., Bi, Q., Zhu, J., Zhang, Q., Jin, C., Lu, L., Lin, X., 2017. Effects of

722 organic amendment on soil aggregation and microbial community composition during 723 drying-rewetting alternation. Sci. Total Environ. 574, 735-743.

724 doi:10.1016/j.scitotenv.2016.09.112

725 Vance, E.D., Brookes, P.C., Jenkinson, D.S., 1987. An extraction method for measuring 726 soil microbial biomass C. Soil Biol. Biochem. 19, 703-707. doi:10.1016/0038$727 \quad 0717(87) 90052-6$

728 Wang, Y.S., Chen, W.C., Lin, L.C., Yen, J.H., 2010. Dissipation of herbicides 729 chlorsulfuron and imazosulfuron in the soil and the effects on the soil bacterial 730 community. J. Environ. Sci. Heal. Part B 45, 449-455. 731 doi:10.1080/03601231003800180

732 Wu, X., Xu, J., Dong, F., Liu, X., Zheng, Y., 2014. Responses of soil microbial 733 community to different concentration of fomesafen. J. Hazard. Mater. 273, 155-164. 734 doi: 10.1016/j.jhazmat.2014.03.041

735 Zhang, C., Liu, X., Dong, F., Xu, J., Zheng Y., 2010. The effect of imazethapyr on soil 736 microbes in soybean fields in northeast China. Chem. Ecol. 26, 173-182. doi: $737 \quad 10.1080 / 02757541003785817$

738 Zornoza, R., Acosta, J.A., Faz, A., Bååth, E., 2016. Microbial growth and community 739 structure in acid mine soils after addition of different amendments for soil reclamation. 740 Geoderma 272, 64-72. doi:10.1016/j.geoderma.2016.03.007 
Fig 1: Microbial biomass for unamended soil (Soil) and soil amended with green compost (Soil+GC) in absence or presence of triasulfuron (TSF) and/or prosulfocarb (PSC). Data present the mean \pm standard deviation of three replicated plots. Different lowercase and uppercase letters indicate significant differences between treatments at the same sampling time and between sampling times within the same treatment (Duncan post-hoc test; $p \leq 0.05$ ), respectively. Lack of letters indicates no significant differences.

Fig 2: Soil respiration for unamended soil (Soil) and soil amended with green compost (Soil+GC) in absence or presence of triasulfuron (TSF) and/or prosulfocarb (PSC). Data present the mean \pm standard deviation of three replicated plots. Different lowercase and uppercase letters indicate significant differences between treatments at the same sampling time and between sampling times within the same treatment (Duncan post-hoc test; $p \leq 0.05)$, respectively.

Fig 3: Dehydrogenase activity for unamended soil (Soil) and soil amended with green compost (Soil+GC) in absence or presence of triasulfuron (TSF) and/or prosulfocarb (PSC). Data present the mean \pm standard deviation of three replicated plots. Different lowercase and uppercase letters indicate significant differences between treatments at the same sampling time and between sampling times within the same treatment (Duncan post-hoc test; $p \leq 0.05$ ), respectively. Lack of letters indicates no significant differences.

Fig 4: Relative abundance (\% mol) of PLFAs specifically diagnostic of Gram-negative and Gram-positive bacteria, Actinomycete and fungi in the unamended soil (Soil) and soil amended with green compost (Soil+GC) before (-7 days) and after (0, 30 and 100 days) triasulfuron (TSF) and/or prosulfocarb (PSC) application. Data present the mean \pm 
standard deviation of three replicated plots. Different lowercase and uppercase letters indicate significant differences between treatments at the same sampling time and between sampling times within the same treatment (Duncan post-hoc test; $p \leq 0.05$ ), respectively. Lack of letters indicates no significant differences.

Fig 5: Ratio Gram-positive / Gram-negative bacteria in unamended soil (Soil) and soil amended with green compost (Soil+GC) in absence or presence of triasulfuron (TSF) and prosulfocarb (PSC). Data present the mean \pm standard deviation of three replicated plots. Different lowercase and uppercase letters indicate significant differences between treatments at the same sampling time and between sampling times within the same treatment (Duncan post-hoc test; $p \leq 0.05$ ), respectively.

Fig 6: Principal component analysis (PCA) showing loading scores for Gram-negative and Gram-positive bacteria, Actinomycete, fungi, dehydrogenase activity, C-microbial biomass, soil respiration, soil organic carbon content (OC), percentage of remaining TFS and PSC and sampling time and scores of each treatment (GC: green compost; TSF:triasulfuron; PSC: prosulfocarb) and sampling time (0 days: circles; 30 days: triangles; 100 days: squares) on the two main principal components. Unamended and GC-amended soils were denoted by blue and green colors, respectively. Percent variability explained by each principal component is shown in parentheses after each axis legend $(n=3)$. 


\section{Table 1}

Remaining percentages of triasulfuron and prosulfocarb in unamended soil and green compost amended soil at 30 and 100 days after application of individual or combined formulations of herbicides.

\begin{tabular}{|c|c|c|c|c|}
\hline \multirow{2}{*}{$\begin{array}{l}\text { Herbicide } \\
\text { (Formulation) }\end{array}$} & \multicolumn{2}{|c|}{ Soil } & \multicolumn{2}{|c|}{ Soil+Green Compost } \\
\hline & 30 days & 100 days & 30 days & 100 days \\
\hline Trisulfuron $\left(\right.$ Logran ${ }^{\circledR}$ ) & $29 \pm 7$ & $2.2 \pm 0.2$ & $62 \pm 15$ & $7.9 \pm 3.8$ \\
\hline Prosulfocarb (Auros ${ }^{\circledR}$ ) & $25 \pm 17$ & $0.4 \pm 0.1$ & $26 \pm 10$ & $1.4 \pm 0.6$ \\
\hline Trisulfuron (Auros Plus $\left.{ }^{(}\right)$ & $51 \pm 18$ & $2.4 \pm 2.2$ & $41 \pm 7.1$ & $9.4 \pm 3.2$ \\
\hline Prosulfocarb (Auros Plus ${ }^{\circledR}$ ) & $37 \pm 17$ & $0.7 \pm 0.4$ & $20 \pm 5.1$ & $2.1 \pm 0.7$ \\
\hline
\end{tabular}




\section{Table 2}

Pearson correlation coefficients between relative percentage of Gram-negative and Gram-positive bacteria, Actinobacteria and fungi, soil dehydrogenase activity (DHA), soil respiration, soil biomass and organic carbon, percentage of remaining triasulfuron and prosulfocarb and ratio Gram-negative / Grampositive bacteria. Significant correlations were denoted by asterisks and bold fond.

\begin{tabular}{|c|c|c|c|c|c|c|c|c|c|c|c|}
\hline & Gram- & Gram+ & Actinobacteria & Fungi & DHA & Respiration & Biomass & OC & Triasulfuron & Prosulfocarb & Gram+/Gram- \\
\hline Gram- & 1 & & & & & & & & & & \\
\hline Gram+ & $-0.904^{* * * *}$ & 1 & & & & & & & & & \\
\hline Actinobacteria & $0.820^{* * * *}$ & $-0.752^{* * * *}$ & 1 & & & & & & & & \\
\hline Fungi & -0.113 & -0.051 & -0.233 & 1 & & & & & & & \\
\hline DHA & -0.247 & $0.449 *$ & -0.333 & -0.025 & 1 & & & & & & \\
\hline Respiration & $0.502^{*}$ & $-0.487^{*}$ & 0.207 & -0.032 & 0.001 & 1 & & & & & \\
\hline Biomass & -0.020 & -0.184 & -0.220 & 0.014 & 0.221 & $0.521^{* *}$ & 1 & & & & \\
\hline $\mathrm{OC}$ & -0.053 & 0.165 & -0.05 & -0.248 & $0.436^{*}$ & 0.306 & $0.432^{*}$ & 1 & & & \\
\hline Triasulfuron & $-0.436^{*}$ & $0.447^{*}$ & -0.334 & 0.200 & 0.126 & $-0.439^{*}$ & -0.075 & -0.055 & 1 & & \\
\hline Prosulfocarb & -0.404 & $0.452^{*}$ & -0.388 & 0.089 & 0.255 & -0.320 & -0.113 & -0.118 & 0.298 & 1 & \\
\hline Gram+/Gram- & $-0.942^{* * * *}$ & $0.989^{* * * *}$ & $-0.765^{* * * *}$ & -0.007 & 0.385 & $-0.518^{* * *}$ & -0.169 & 0.084 & $0.473^{*}$ & $0.451^{*}$ & 1 \\
\hline
\end{tabular}




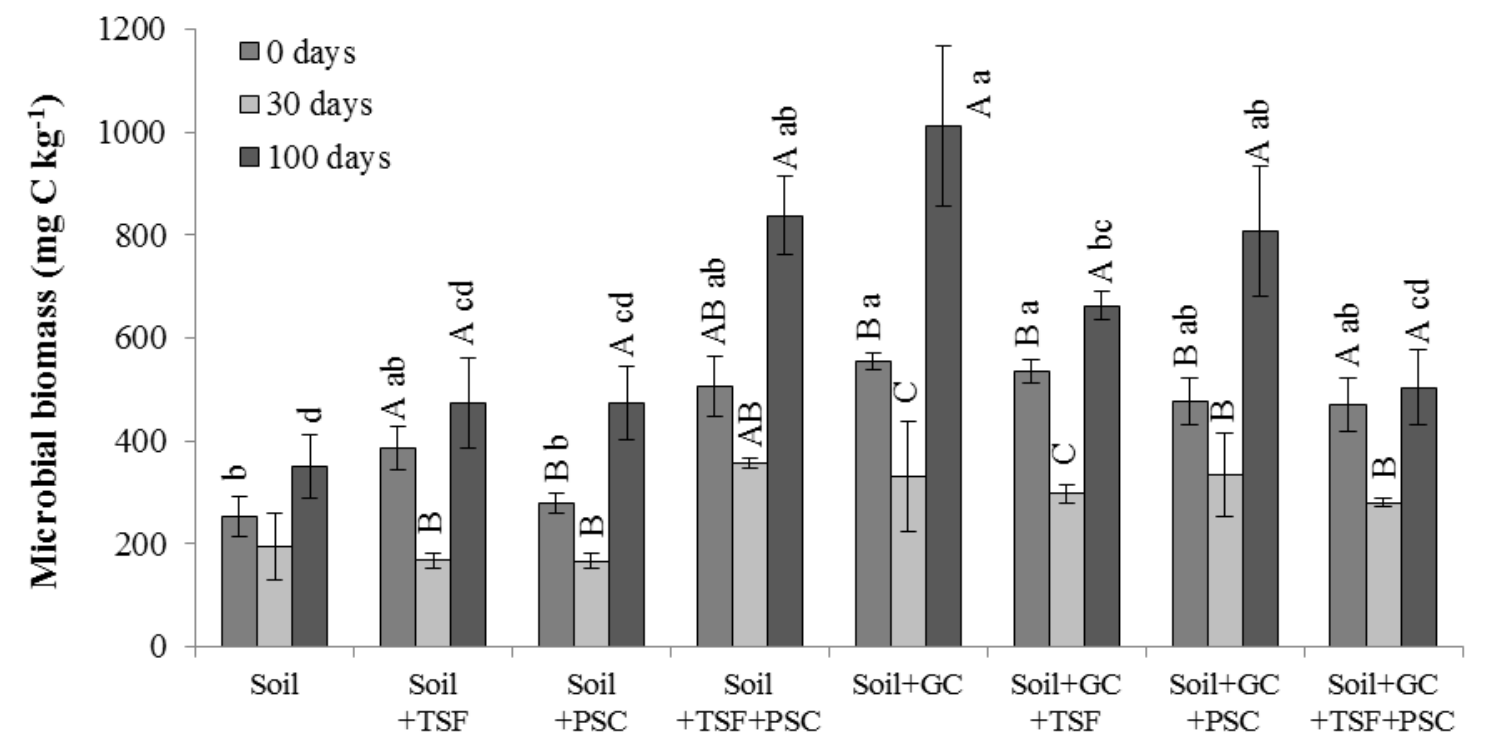

Fig. 1 


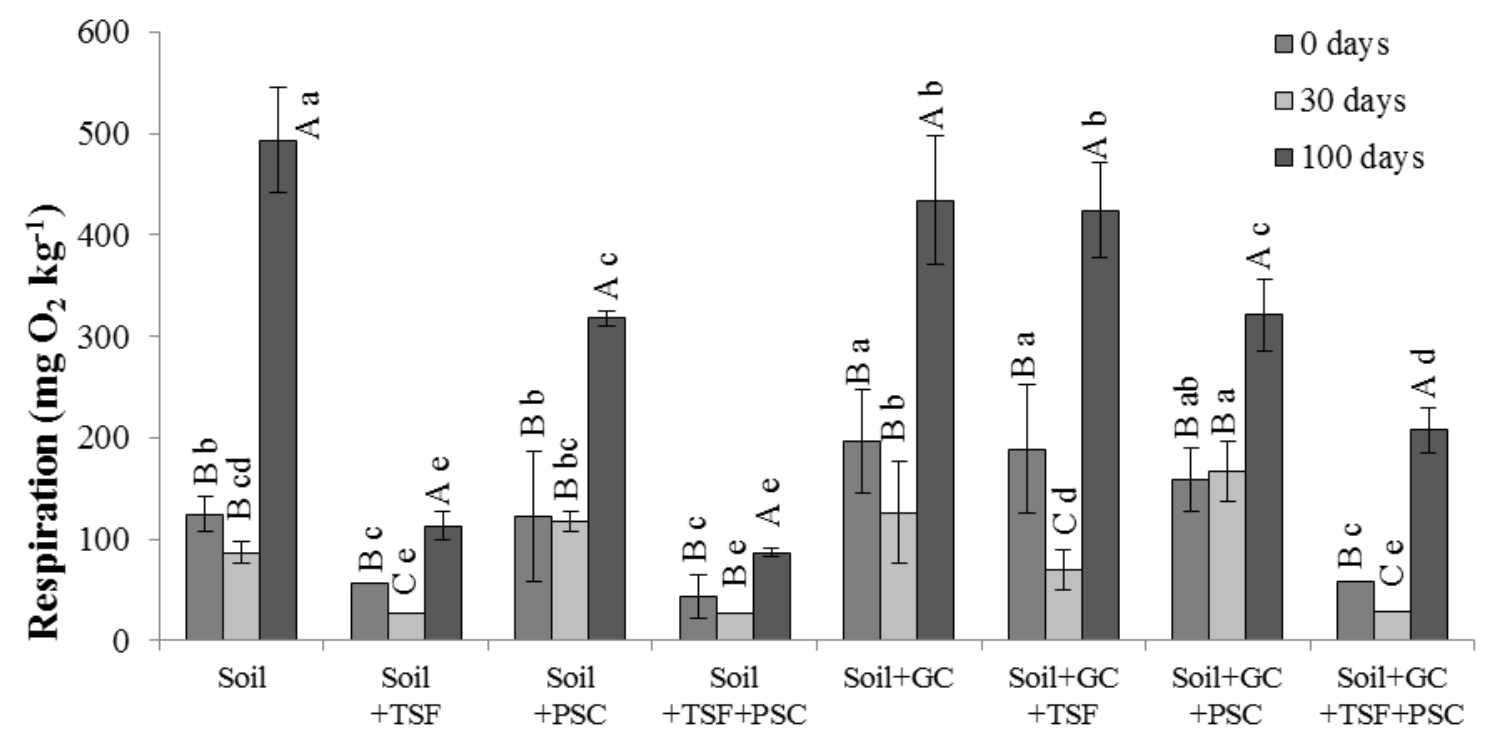

Fig. 2 


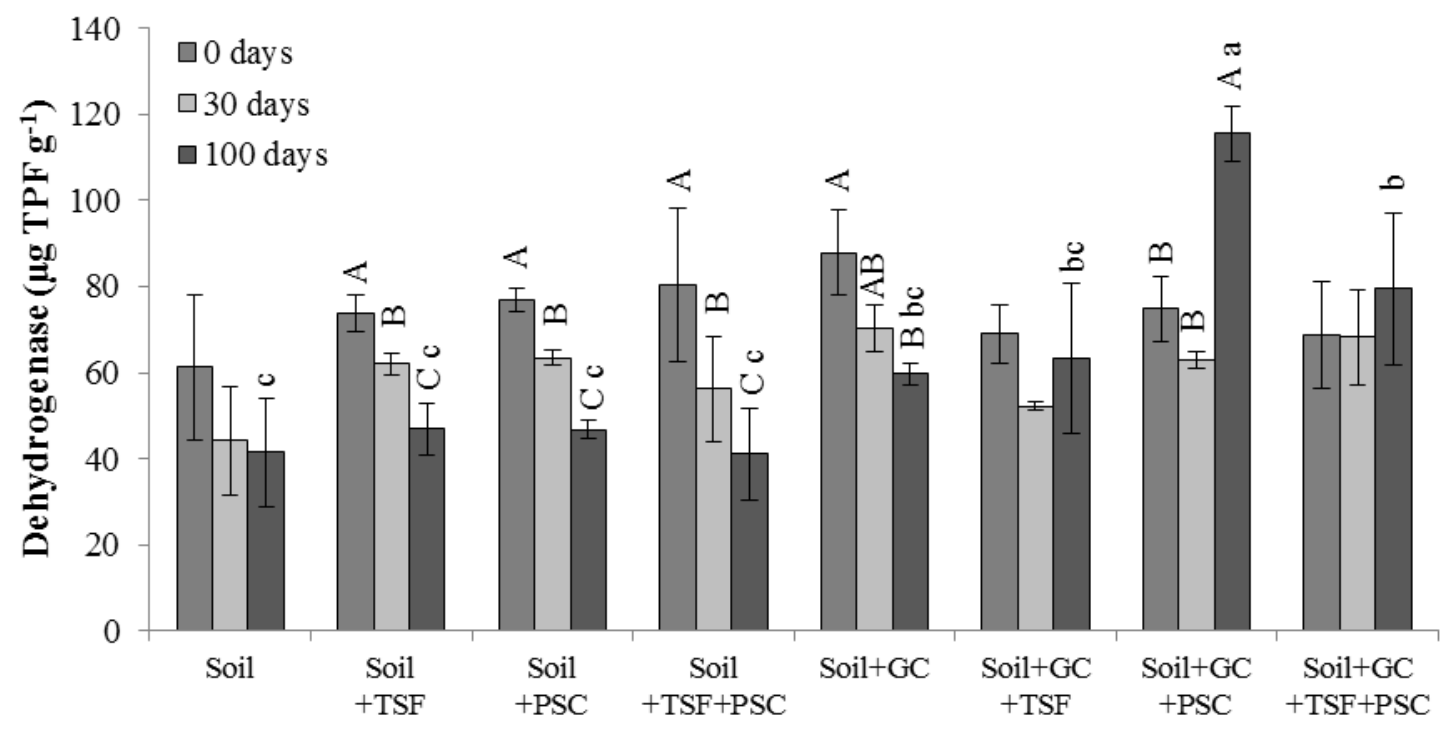

Fig. 3 

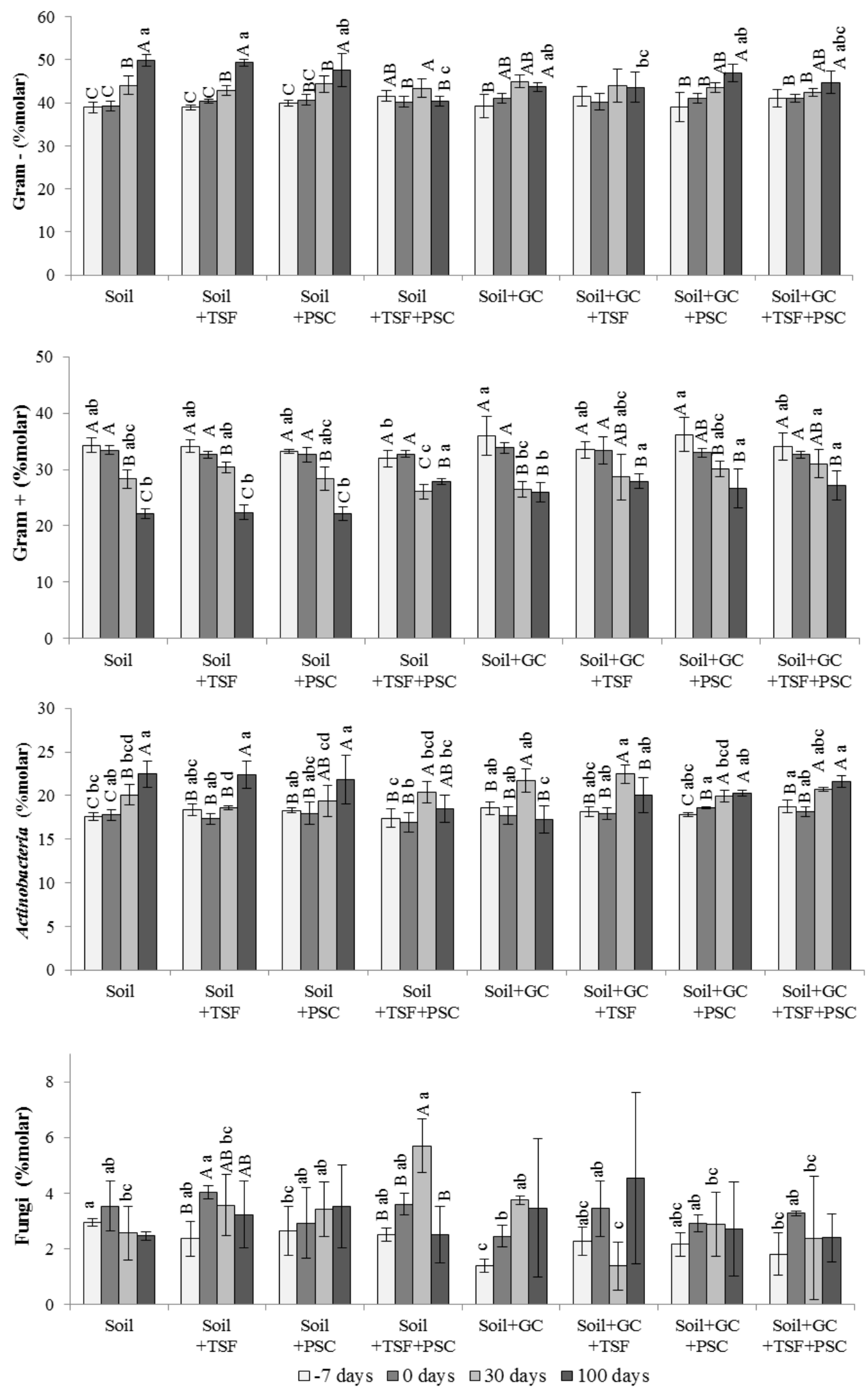

Fig. 4 


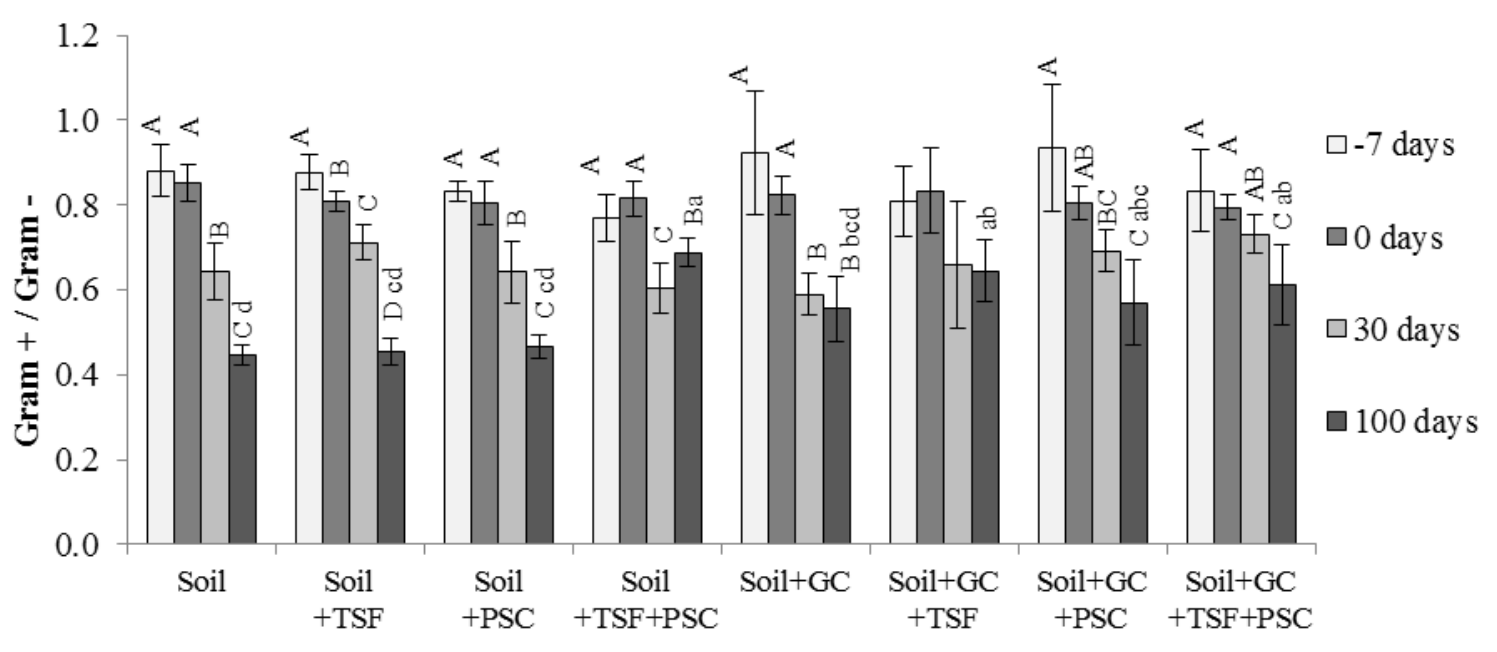

Fig. 5 


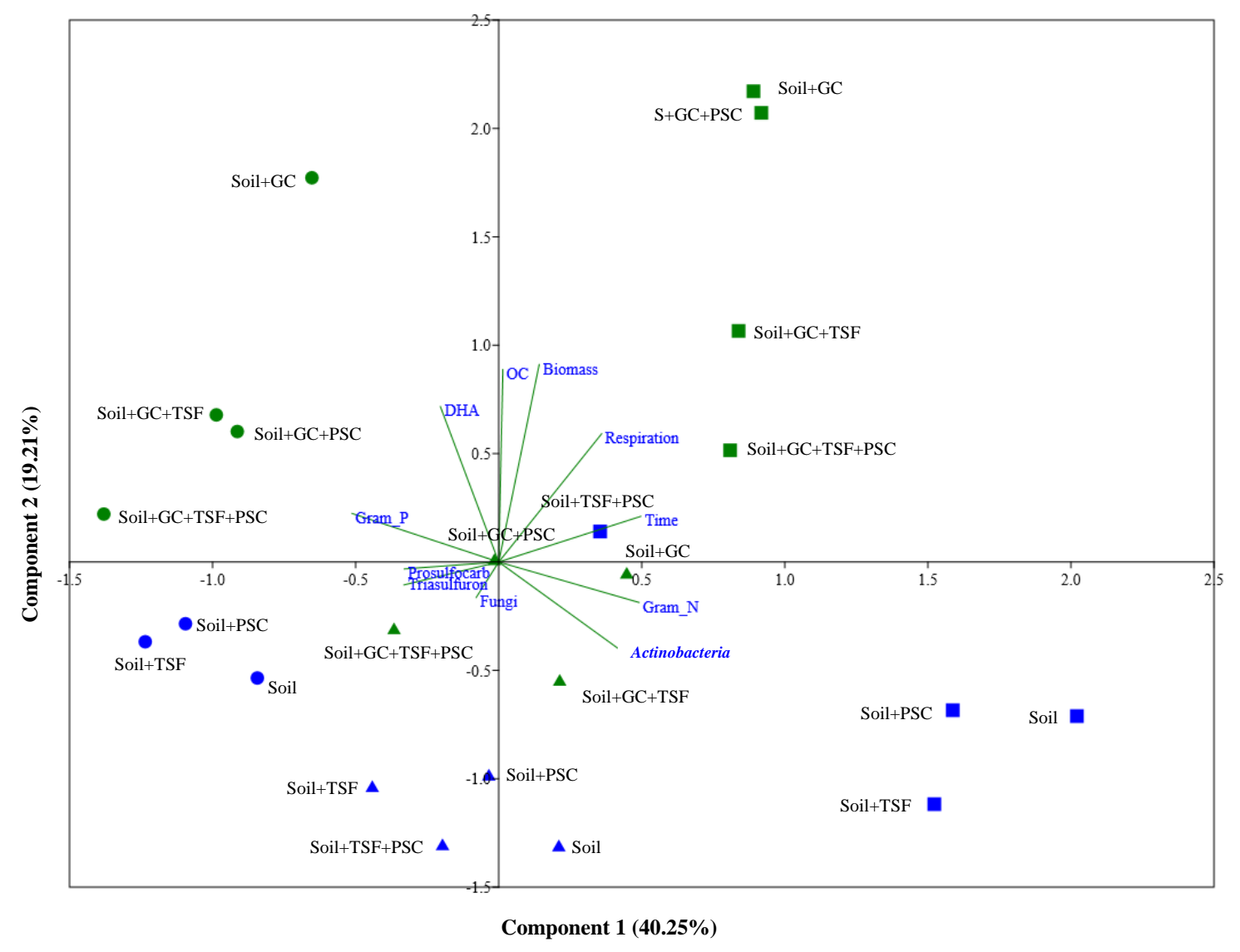

Fig. 6 


\section{SUPPLEMENTARY MATERIAL}

\section{Simultaneous application of two herbicides and green compost in a field experiment: Implications on soil microbial community}

C. García-Delgado, V. Barba, J.M. Marín-Benito, J.M. Igual, M.J. Sánchez-Martín, M.S. Rodríguez-Cruz*

Instituto de Recursos Naturales y Agrobiología de Salamanca (IRNASA-CSIC), Cordel de Merinas 40-52, 37008 Salamanca, Spain.

\section{*Corresponding author.}

E-mail address: msonia.rodriguez@irnasa.csic.es

Tel.: +34 923219606. Fax: +34923219609

Number of Pages: 5

Number of Tables: 2 
Table S1.

Physicochemical characteristics of herbicides (PPDB, 2017).

\begin{tabular}{|c|c|c|}
\hline & Triasulfuron & Prosulfocarb \\
\hline $\begin{array}{l}\text { Chemical name } \\
\text { (IUPAC) }\end{array}$ & $\begin{array}{l}\text { 1-[2-(2- } \\
\text { chloroethoxy)phenylsulfonyl]-3-(4- } \\
\text { methoxy-6-methyl-1,3,5-triazin-2- } \\
\text { yl)urea }\end{array}$ & $\begin{array}{l}S \text {-benzyl } \\
\text { dipropyl(thiocarbamate) }\end{array}$ \\
\hline \multicolumn{3}{|l|}{$\begin{array}{l}\text { Chemical } \\
\text { structure }\end{array}$} \\
\hline $\begin{array}{l}\text { Water solubility } \\
\left(\mathrm{mg} \mathrm{L}^{-1}\right)\end{array}$ & $815\left(20^{\circ} \mathrm{C}, \mathrm{pH} 7\right)$ & $13.0\left(20^{\circ} \mathrm{C}, \mathrm{pH} 6.1\right)$ \\
\hline $\log$ Kow & $-0.59\left(20^{\circ} \mathrm{C}, \mathrm{pH} 7\right)$ & $4.48\left(20^{\circ} \mathrm{C}, \mathrm{pH} 7\right)$ \\
\hline $\begin{array}{l}\mathrm{DT}_{50} \text { (laboratory) } \\
\text { (days) }\end{array}$ & 59.1 & 12.4 \\
\hline $\begin{array}{l}\mathrm{DT}_{50} \text { (field) } \\
\text { (days) }\end{array}$ & 38.5 & 9.8 \\
\hline $\mathrm{pKa}$ & $4.64\left(\right.$ at $\left.25^{\circ} \mathrm{C}\right)$ & - \\
\hline Gus index & 5.12 & 0.84 \\
\hline
\end{tabular}




\section{Table S2.}

Properties of the unamended soil and green compost amended soil from experimental plots $(0-10 \mathrm{~cm})$

\begin{tabular}{lll}
\hline Properties & Soil & Soil+GC \\
\hline Soil texture & Sandy clay loam & Sandy clay loam \\
$\mathrm{pH}$ & 7.81 & $7.13-7.39^{\dagger}$ \\
Bulk density $\left(\mathrm{g} \mathrm{cm}^{-3}\right)$ & 1.39 & 1.00 \\
$\mathrm{OC}(\%)$ & 1.30 & $2.21-2.36^{\dagger}$ \\
$\mathrm{DOC}(\%)$ & 0.002 & $0.015-0.019^{\dagger}$ \\
$\mathrm{N}(\%)$ & 0.14 & $0.23-0.25^{\dagger}$ \\
$\mathrm{C} / \mathrm{N}$ & 9.28 & $9.44-9.61^{\dagger}$ \\
$\mathrm{CaCO}$ & $(\%)$ & \\
Sand $(\%)$ & 0.21 & \\
Silt $(\%)$ & 57.63 & \\
Clay $(\%)$ & 16.97 & \\
Clay mineralogy & 24.98 & \\
\hline
\end{tabular}

${ }^{\dagger}$ Value ranges correspond to mean values of three plots at different sampling times. ${ }^{\dagger} \mathrm{K}$, kaolinite; I, illite; M, montmorillonite. 


\section{Experimental set up}

The field experiment was conducted in an agricultural sandy clay loam soil (Typic Haploxerept) located in the experimental farm Muñovela belonging to the Institute of Natural Resources and Agrobiology of Salamanca, Spain (4055'56”N latitude, 5'52'53'W longitude). Rainfall and air temperature were monitored over the 100 days of experimentation at a meteorological station installed on site. An experimental layout of randomized complete blocks was designed in February 2015 with eight treatments and three replicates per treatment (24 plots of $3 \mathrm{~m} \times 3 \mathrm{~m}$ ) corresponding to unamended soil (12 plots) and soil amended with GC at the rate of 120 $\mathrm{t} \mathrm{ha}^{-1}$ on a dry weight basis $\left(\sim 11.6 \mathrm{t} \mathrm{C} \mathrm{ha}^{-1}\right)$ (12 plots). Three unamended and three amended plots were treated with single commercial formulations of each herbicide $\left(\operatorname{Logran}^{\circledR}\right.$ and Auros $^{\circledR}$ ), or a combined commercial formulation of both herbicides (Auros Plus ${ }^{\circledR}$ ). Three more control plots (unamended and amended) did not receive any herbicide. Prior to soil amendment, the soil was tilled using a field cultivator, and then GC was manually mixed with the topsoil $(0-20 \mathrm{~cm})$ in each plot. The study was conducted in the cereal growing season, but the plots were left fallow.

\section{Herbicides extraction and analysis}

Duplicate subsamples of moist soil $(6 \mathrm{~g})$ from each plot were transferred to a glass tube, and extracted with methanol $(12 \mathrm{~mL})$. The samples were sonicated for $1 \mathrm{~h}$, shaken at $20^{\circ} \mathrm{C}$ for $24 \mathrm{~h}$, and then centrifuged at $5045 \mathrm{~g}$ for $15 \mathrm{~min}$ and filtered to remove particles $>0.45 \mu \mathrm{m}$ in a GHP Acrodisc filter (Waters Corporation). A volume of $8 \mathrm{~mL}$ was transferred to a clean glass tube and evaporated until dryness at $25^{\circ} \mathrm{C}$ under a nitrogen stream using an EVA-EC2-L evaporator (VLM GmbH, Bielefeld, Germany). The residue was dissolved in $0.5 \mathrm{~mL}$ of methanol+formic acid (1\%), and transferred to a HPLC glass vial for analysis. 
The analysis of triasulfuron and prosulfocarb was performed by HPLC. The apparatus used was a Waters chromatograph (Waters Assoc., Milford, MA, USA), equipped with a model e2695 multisolvent delivery and autosampler system attached to a ZQ mass spectrometer detector (MS), with Empower software as the data acquisition and processing system. A Luna ${ }^{\circledR} 3 \mu \mathrm{m} \operatorname{PFP}(2) 100 \AA(150 \times 4.6 \mathrm{~mm})$ column by Phenomenex (Torrance, CA, USA) was used at ambient temperature, and the mobile phase was acetonitrile:water $+1 \%$ formic acid (70:30). The flow rate of the mobile phase was $0.4 \mathrm{~mL} \mathrm{~min} \mathrm{~m}^{-1}$ and the sample injection volume was $10 \mu \mathrm{L}$. Detection involved monitoring the positive molecular ion $[\mathrm{m} / \mathrm{z}] 402.8$ (triasulfuron) and 252.4 (prosulfocarb) and the retention times were $6.1 \mathrm{~min}$ and $14.1 \mathrm{~min}$, respectively. The matrix-based calibration standards were between 0.1 to $2.5 \mu \mathrm{g} \mathrm{mL}^{-1}$ for both herbicides, and the limit of detection (LOD) and limit of quantification (LOQ) were in the ranges $0.018-0.026$ or $0.059-0.088 \mu \mathrm{g} \mathrm{mL}^{-1}$ for triasulfuron and $0.005-0.008$ or $0.017-0.027 \mu \mathrm{g}$ $\mathrm{mL}^{-1}$ for prosulfocarb in the unamended and amended soils, respectively. The method's recoveries were determined by spiking three unamended and amended soil samples with analytical grade triasulfuron or prosulfocarb at similar concentrations to those applied in the field, and performing the extraction procedure as described above. The mean recovery values for a level spiking of $76.9 \mu \mathrm{g} \mathrm{kg}^{-1}$ (triasulfuron) and $3.46 \mathrm{mg} \mathrm{kg}^{-1}$ (prosulfocarb) were $>80 \%$ for triasulfuron applied individually $\left(\operatorname{Logran}^{\circledR}\right)$ or in combined form (Auros Plus ${ }^{\circledR}$ ), and $>90 \%$ or $>70 \%$ for prosulfocarb applied individually $\left(\right.$ Auros $^{\circledR}$ ) or combined form (Auros Plus ${ }^{\circledR}$ ) for the unamended and GC-amended soils.

\section{References}

PPDB, Pesticide Properties Database, 2017. Agriculture \& Environment Research Unit (AERU). University of Hertfordshire http://sitem.herts.ac.uk/aeru/ppdb/en/ (accessed July 2017). 
